\title{
Article
}

\section{Characteristics of clinical measurements between biomechanical responders and non-responders to a shoe designed for knee osteoarthritis}

Kim, Yongwook, Richards, James, Lidtke, Roy H and Trede, Renato Available at http://clok.uclan.ac.uk/20358/

Kim, Yongwook, Richards, James ORCID: 0000-0002-4004-3115, Lidtke, Roy H and Trede, Renato (2018) Characteristics of clinical measurements between biomechanical responders and non-responders to a shoe designed for knee osteoarthritis. Gait \& Posture, 59 . pp. 23-27. ISSN 0966-6362

It is advisable to refer to the publisher's version if you intend to cite from the work. http://dx.doi.org/10.1016/j.gaitpost.2017.09.038

For more information about UCLan's research in this area go to http://www.uclan.ac.uk/researchgroups/ and search for <name of research Group>.

For information about Research generally at UCLan please go to http://www.uclan.ac.uk/research/

All outputs in CLoK are protected by Intellectual Property Rights law, including Copyright law. Copyright, IPR and Moral Rights for the works on this site are retained by the individual authors and/or other copyright owners. Terms and conditions for use of this material are defined in the policies page. 
Original article

Title: Characteristics of clinical measurements between biomechanical responders and non-responders to a shoe designed for knee osteoarthritis

Yongwook Kim ${ }^{1}, \mathrm{PhD}$, Jim Richards², PhD, Roy H. Lidtke, DPM, Renato Trede ${ }^{3}$, PhD.

${ }^{1}$ Department of Physical Therapy, College of Medical Sciences, Jeonju University, Republic of Korea.

${ }^{2}$ Allied Health Research unit, University of Central Lancashire, UK

${ }^{3}$ Departamento de Fisioterapia, Universidade Federal dos Vales do Jequitinhonha e Mucuri, Brazil

\section{Correspondence and reprint requests to Prof Jim Richards, PhD,}

Address correspondence to Prof Jim Richards, Allied Health Research unit, University of Central Lancashire, Brook Building, Preston, Lancashire, UK, PR1 2HE

TEL: +44 (0) 1772-89-4575, E-mail: jrichards@uclan.ac.uk

\section{Acknowledgements}

The shoes were supplied by DJO Global, Inc. The suppliers played no role in the design, execution, analysis and interpretation of the data or writing of this study. This research did not receive any specific grant from funding agencies in the public, commercial, or not-for-profit sectors. 
Abstract. [Purpose] The purpose of this study was to investigate the characteristics of biomechanical and clinical measurements in relation to the knee adduction moment when wearing a standard shoe and a shoe design for individuals with knee osteoarthritis (Flex-OA). [Methods] Kinematic and kinetic data were collected from thirty-two healthy individuals (64 knees) using a ten camera motion analysis system and four force plates. Subjects performed 5 walking trials under the two conditions and the magnitude of individuals' biomechanical responses where explored in relation to the clinical assessment of the Foot Posture Index, hip rotation range, strength of hip rotators, and active ankle-foot motion, all of which have been described as possible compensation mechanisms in knee osteoarthritis. [Results] Significant reductions in the first peak of the knee adduction moment (KAM) during stance phase $(9.3 \%)$ were recorded $(\mathrm{p}<0.0001)$. However, despite this difference, 22 of 64 knees showed either no change or an increased KAM, indicating a non-response or negative-response to the Flex-OA shoe. Significant differences were observed between the responder and non-responder subgroups in the hip rotation range ratio $(p=0.044)$ and the hip rotators strength ratio $(p=0.028)$. [Conclusion] Significant differences were seen in clinical assessments of hip rotation range and hip rotator strength between responders and non-responders using a cut-off of $0.02 \mathrm{Nm} / \mathrm{kg}$ change in the KAM.

Key words: Knee adduction moment, Hip rotation, Knee osteoarthritis 


\section{Introduction}

Knee osteoarthritis $(\mathrm{OA})$ is the most prevalent disease amongst individuals aged 50 years and

older in South Korea, affecting approximately 12.5\% [1]. Clinical characteristics of knee OA are: pain, decreased range of motion, joint instability, muscle weakness, joint stiffness, and proprioceptive loss, all of which decrease quality of life [2].

The knee adduction moment (KAM) during walking in patients with degenerative knee OA has been discussed in previous studies [3 - 6]. The KAM is primarily calculated by the ground reaction force and its lever arm. The KAM contributes to adduction of the knee and genu-varus deformities, which are significantly correlated with OA severity [7]. Therefore, reduction of the external KAM during walking is clinically important for treatment of OA. Biomechanical interventions such as: orthotic shoe inserts [8], knee braces [9, 10], and specialized footwear [11 - 14] for knee OA aim to improve pain, decrease joint loading, and delay disease progression.

Over the past two decades, specialized footwear has been developed for the potential conservative management of knee OA [12]. Recently, Shakoor et al. reported that, following use of specialized mobility footwear, the Flex-OA shoe, the KAM was reduced by $18 \%$ compared to use of the participants' own shoe [14]. Although the Flex-OA shoe had a significant effect on KAM, no study has explored whether this effect is universal or whether responder and non-responder groups may exhibit differences in clinical and biomechanical measurements. Therefore, the purpose of this study was to explore differences in KAM in a healthy population when wearing a standard shoe and the 
Flex-OA shoe, and to investigate the characteristics of individuals' responses from biomechanical and clinical assessments.

\section{METHODS}

Participants

This study recruited 32 healthy volunteers who consented to participate in the study and met the selection criteria. There were twenty-four males and eight females in the study population. Participants were given a detailed explanation of the study procedure and written informed consent was obtained. This study was conducted in accordance with the principles of the Declaration of Helsinki and was approved by the STEMH Ethics Committee of the University of Central Lancashire (STEMH 347).

Volunteers who were able to walk freely for $10 \mathrm{~m}$ were recruited for this study. Volunteers who had any neurological, musculoskeletal, or cardiopulmonary problems were excluded. The mean age, height, and weight of all participants were $30.4 \pm 11.5$ years, $174.5 \pm 9.6 \mathrm{~cm}$, and $72.3 \pm 12.9 \mathrm{~kg}$, respectively.

\section{Instrumentation and procedure}

A Qualisys Motion Capture System (Qualisys, Gothenburg, Sweden) was used to collect threedimensional kinematic and kinetic data from participants walking along a $10 \mathrm{~m}$ walkway wearing a 
standard shoe (control) and the Flex-OA shoe. Qualisys Track Manager software (Qualisys,

Gothenburg, Sweden) was used to obtain data using ten Oqus-7 cameras (Qualisys, Gothenburg,

Sweden) sampling data at $100 \mathrm{~Hz}$. The camera system was synchronised with four BP400600 force

platforms (AMTI, Massachusetts, USA), which were embedded in the middle of the walkway and sampled data at $500 \mathrm{~Hz}$. A $750 \mathrm{~mm}$ calibration wand was used to calibrate the motion capture system and an L-frame reference object was used to identify the lab origin.

Changes in joint angles and moments of 32 subjects (64 healthy knees) were measured during walking when wearing the Flex-OA shoe (DJO Global, Vista, CA, USA) and a standardised shoe (Athletic footwear, DJO Global, Vista, CA, USA), which were tested in a randomised order. For the dynamic walking conditions, participants wore 52 retro reflective markers $(14 \mathrm{~mm})$, which were attached bilaterally onto the: pelvis, thigh, leg, and shoes over the rearfoot, midfoot and forefoot. Additional markers were placed bilaterally over the following anatomical locations: malleoli, femur epicondyles, greater trochanters, and anterior and posterior superior iliac spines. Marker clusters of four markers were affixed bilaterally on the shank and thigh according to the six-degrees-of-freedom (6DOF) model [15] (Figure 1). Initially, a static trial was taken, which served as an anatomical calibration file. Participants were then asked to walk along a $10 \mathrm{~m}$ walkway in the laboratory at their self-selected walking speed. A total of 5 walking trials were collected for each shoe condition and data were obtained bilaterally. Participants were not given any walking instructions other than to walk at their self-selected speed and were allowed adequate rest if needed. In trials where participants did not 
make complete foot contact on the force plate, kinetic data from that trial were excluded. The mean of all gait trials of the Flex-OA shoe and the standardised shoe of all participants were $7.4 \pm 2.6$ trials, and $7.2 \pm 1.9$ trials, respectively.

Following data collection, Visual 3D motion analysis software (C-Motion, Rockville, MD, USA) was used to analyse kinematic and kinetic data using the Calibrated Anatomical System Technique with a modified oxford foot model. Kinematic data were low-pass filtered with a $4^{\text {th }}$ order Butterworth filter with a cut-off frequency of $6 \mathrm{~Hz}$. Kinetic data were low-pass filtered using a $4^{\text {th }}$ order Butterworth filter with a cut-off frequency of $15 \mathrm{~Hz}$. KAMs were calculated using inverse dynamic analysis. Figure 2 illustrates examples of KAM during stance phase. The X-Y-Z Cardan sequence was used to define the order of rotations following the Right Hand Rule about the segment coordinate system axes. Joint kinematic and kinetic data were normalized to the gait cycle starting with initial heel contact. GRF data and joint moments were normalized for body weight.

The magnitude of individuals' responses where explored in relation to the clinical assessment of: the Foot Posture Index (FPI), passive hip rotation range, strength of hip rotators, and ankle motion, all of which have been described as possible compensation mechanisms in knee OA [16-18].

The FPI is a clinical diagnostic tool used to quantify the degree to which a foot can be considered to be in a pronated, supinated or neural position [19]. A previous study reported that the FPI exhibited good intra-observer reliability and moderate inter-observer reliability [20]. The six criteria version of the FPI was used to assess foot position on the bilateral foot. Foot position was 
assessed while participants stood in their relaxed standing position with double limb support, arms along each side of the side of the body, and looking straight ahead. The six-items of the FPI were: talar head palpation, supra and infra malleolar curvature, calcaneal frontal plane position, prominence in the region of the talonavicular joint, congruence of the medial longitudinal arch, and abduction/ adduction of the forefoot on the rearfoot, with reference values ranging from -12 (severely supinated) to +12 (severely pronated).

A standard 12-in. plastic, round universal goniometer was used to measure passive hip rotation range of motion (ROM). For measuring hip ROM, participants were placed in the prone position on a firmly padded treatment plinth. The hip being measured was placed in $0^{\circ}$ of abduction, the knee was flexed to $90^{\circ}$ and the leg was passively moved to produce hip internal or external rotation. A mobilization strap was tightened over the sacrum to prevent pelvic movement. The investigator recorded the hip passive rotation ROM when a firm end-feel was noted. Three trials for each motion were performed with a rest period of approximately 1 minute between each trial. The mean value of the trials were used for statistical analysis. Previous studies have reported an intra-class correlation coefficient (ICC) of 0.94-0.99 for intra-rater reliability when this technique is used to measure hip rotation ROM [21].

Strength (force) measures were obtained for left and right hip internal rotation (IR) and external rotation (ER) muscles. The maximum isometric muscle strength (peak force) of the participants' hip rotators was assessed using the Lafayette dynamometer (Lafayette Instrument 
Company, Lafayette, IN, USA) with standardised manual muscle testing procedures [22] and dynamometer placements [23]. The assessment position of the hip rotator strength was similar to the hip rotation ROM measurement procedure. The contact point for the Lafayette dynamometer was 2.5 $\mathrm{cm}$ proximal to the medial and lateral malleolli. The participant was asked to "push" into the padded Lafeyette dynamometer for duration of 5 seconds as hard as they could. Three trials for each strength test were performed with a rest period of approximately 2 minutes between each trial. The mean value of the trials were used for statistical analysis. An ICC for intra-rater reliability using this technique for hip rotator strength assessment, has previously been reported as 0.91-0.96 [21].

An Ankle Foot Motion Test (AFMT) was conducted to measure active maximum rearfoot inversion and eversion range. The subjects were asked stand in a neutral foot position and then invert and evert both feet simultaneously. Twenty-six retro reflective markers were placed bilaterally on the: malleoli, rearfoot, midfoot, and forefoot to analyse the AFMT. For calibration purposes, data were captured for 1 second when the participant stood with their feet shoulder-width apart. The difference between the maximum inversion and eversion ROM of the rearfoot to tibial during AFMT trials was calculated. The mean values for three test trials were used for statistical analysis.

\section{Data analysis}

Data were found to be suitable for parametric testing. A two factor repeated measures ANOVA 
with Bonferroni's correction was used to determine the effect of shoe condition and knee side in stance phase during walking. The magnitude of change in first peak KAM was then used to predict responders and non-responders subgroups. The number of responders was twenty-one subjects (42 knees bilaterally) and the non-responders was eleven ( 22 knees bilaterally). Differences between the responders and non-responders subgroups for the clinical and biomechanical measurements were analysed using independent t-test and Mann-Whitney U test. Statistical analyses were conducted using SPSS version 23.0. Statistical differences were defined as significant at the $\alpha=0.05$ level.

The authors could not find data specific to the minimally clinically important change in KAM. However, significant differences in KAM have been shown in conservative interventions of Knee OA with changes as low as a $0.02 \mathrm{Nm} / \mathrm{kg}$ [24]. In addition, changes of $7 \%$ in KAM have resulted in a $23 \%$ improvement in KOOS score [25], which is greater than the $10 \%$ threshold suggested to be clinically important by Roos and Lohmander [26]. Therefore, a pragmatic threshold of a clinically important reduction of $0.02 \mathrm{Nm} / \mathrm{kg}$, equating to a $5 \%$ change was used in this exploratory study.

\section{Results}

The mean of walking speed in both the Flex-OA shoe and the standardised shoe of all participants were $1.435 \pm 0.126 \mathrm{~m} / \mathrm{s}$, and $1.433 \pm 0.142 \mathrm{~m} / \mathrm{s}$, respectively and there was no significant difference in walking speed between shoe conditions $(\mathrm{p}=0.811)$. Significant differences were observed in the KAMs between conditions and knee sides in various stance phases (Table 1). The first 
peak of the KAM during loading ( 0 - $25 \%$ of stance phase) showed that the Flex-OA shoe condition significantly decreased KAM for both knees $(\mathrm{p}=0.00008)$ (Tables 1 and 2). In addition, there were significant differences in the KAM between shoe conditions and knee sides at mid stance $(p=0.017)$ (Tables 1 and 2). On the right side, the second peak KAM was significantly decreased during late stance phase $(\mathrm{p}=0.001)($ Tables 1 and 2$)$. However, there were no interaction effects between shoe conditions and knee sides in any of the KAM values $(p>0.05)$ (Table 2).

Despite a significant $9.3 \%$ reduction in the first peak (loading) KAM when wearing the FlexOA shoe $(\mathrm{F}=26.018, \mathrm{p}=0.00008)($ Table 2$), 22$ of the 64 knees showed a response of either an increased KAM or no change using a threshold of $0.02 \mathrm{Nm} / \mathrm{kg}$, equating to a $5 \%$ change, indicating a non-response (Figure 3). Therefore, the change in KAM between the Flex-OA and the standardised shoe condition was used to separate the data into two subgroups (42 responders and 22 nonresponders) (Table 3). These subgroups were then used to explore whether any differences existed in the clinical measures. Independent t-tests and Mann-Whitney U tests showed significant differences between responders and non-responders in hip IR/ER rotation $(p=0.044)$ and hip IR/ER strength ratio $(\mathrm{p}=0.028)($ Table 3$)$. However, there were no significant differences in the FPI, hip internal rotation range, hip rotators strength, and all AFMT between subgroups $(\mathrm{p}>0.05)$ (Table 3).

\section{Discussion}


We observed that, in 32 subjects, 22 of 64 healthy knees, experienced negative or minimal effect on KAM during walking when wearing the Flex-OA shoe. Therefore, this study examined whether clinical and biomechanical measurements could distinguish between KAM response/ nonresponse subgroups in healthy individuals.

The clinical and biomechanical measurements used in the study were directly related to the coronal and transverse planes, which are arguably the most important considerations for individuals with knee OA. The results of this study showed that the ratio of hip IR/ER range and the ratio of hip IR/ER strength exhibited significant differences between responders and non-responders subgroups ( $p$ $<0.05)$. Although interventions such as the Flex-OA shoe and lateral wedging have shown considerable, clinically important effects on the KAM in previous studies [11 - 14], hip rotation ranges and strengths may also be important factors which could influence the first peak of the KAM during walking. In this study, the responders subgroup showed a greater value for hip ER ROM $\left(53.0^{\circ}\right)$ than hip IR $\left(41.2^{\circ}\right)$. On the other hand, the non-responders subgroup showed greater hip ER ROM $\left(41.2^{\circ}\right)$ than IR $\left(43.7^{\circ}\right)$. Therefore, the IR/ER ratio of the hip rotation range was significantly different between subgroups ( $\mathrm{p}=0.044$ ), with the responders having an IR/ER ratio $\leq 1$, whereas the non-responders' ratio was $\geq 1$. Studies performed on healthy subjects have consistently shown that the bilateral hip IR/ER rotation is consistently equal and have reported little difference between IR and ER of the hip, with differences ranging from as little as 1 to 5 degrees [27 -29]. Previous studies have suggested that a greater difference between hip IR and ER range, is linked to a more "abnormal" 
alignment of the lower extremity including: tibial torsion, genu valgum, genu varum, pes equinus, pes planus, and metatarsus varus [30 - 33]. It has also been reported that individuals with a lower extremity movement impairment syndrome are usually characterised by increased hip IR, increased knee valgus, and excessive foot pronation $[34,35]$. On the other hand, increased knee varus alignment has been associated with a greater risk of medial knee OA progression [36]. From a biomechanical perspective, the increased KAM is directly linked to the knee varus alignment which, in turn, contributes knee OA progression [37, 38]. Therefore, responders to the Flex-OA shoe exhibit characteristics that can be more closely linked with knee OA progression, namely the hip IR/RE ratio, than those of non-responders.

Although individually hip IR and ER strength exhibited no significant difference between responders and non-responders subgroups $(\mathrm{p}>0.05)$, the hip IR/ER strength ratio showed a significant difference between subgroups ( $\mathrm{p}=0.028$ ), indicating a difference in the balance of IR/ER strength. These results were similar to those of hip IR/ER ROM assessments, indicating a possible link between hip rotators strength and hip rotation ROM. Cibulka et al [21] showed evidence that greater hip ER range compared to IR range may contribute to weakness of hip internal rotator muscles, whereas those with greater hip IR range often exhibit weakness of the hip external rotator muscles.

In this study, the FPI and AFMT were used to measure static ankle-foot alignments and dynamic motions and showed no significant differences in all variables investigated. To the authors' knowledge, no studies have investigated the difference in FPI score and active ankle-foot movement 
range between two subgroups. However, a previous study identified normative values for differences in FPI scores across feet by providing cut-off limits between normal difference and asymmetrical differences [39]. This study reported that a normal reference range between \pm 1 SD from the mean was -2 to +2 . In the current study, mean FPI score of two subgroups ranged between 2.16 to 2.89 . As most of the participants had normal ankle-feet alignment, there were no significant differences in FPI score and AFMT evaluation between responders and non-responders subgroups. However, these may be important measures in other clinical presentations of knee OA.

This was an exploratory study conducted on healthy individuals, who were mostly younger than the general age range of those suffering from knee OA. The purpose was to determine if biomechanical response to footwear can be predicted from clinical assessment, however as this was performed on healthy individuals there is a limitation to generalize these results to individuals with knee OA. Further exploration of different clinical assessment scores, including the ones identified in this study, is therefore required in patients with knee OA. Such assessments (i.e. Q angle, knee varus angle, Craig's test) may be suitable as clinical predictors for responders and non-responders to footwear interventions. More work is required to explore if subgroups exist in patients with knee OA, and if so, optimal cut-off thresholds for the different clinical measures should be investigated. This information would improve our understanding of the effectiveness of different conservative interventions and would assist with identification of relevant interventions for the different subgroups. 


\section{Conflict of interest statement}

We can confirm that there is no conflict of interests for any of the authors.

\section{Table Legends}

Table 1. Mean values of coronal plane knee moments in stance phase $(\mathrm{N}=32)$

Table 2. Repeated measure ANOVA comparing coronal plane knee moments under the shoe conditions and knee sides in stance phase during walking $(\mathrm{N}=32)$

Table 3. Mean values of clinical and biomechanical assessments and t-tests between responders and non-responders

\section{Figure Legends}

Figure 1. Marker positions on lower limbs and pelvic during static calibration and walking trials.

Figure 2. Intra-individual variability of knee adduction moment during stance phase. Flex-OA shoe moment (solid line) and standardized shoe moment (dot line) from 25 repetitive trials (thin line) and their average (thick lines).

Figure 3. Biomechanical responders/non-responders to the Flex-OA shoe defined by a threshold of a $0.02 \mathrm{Nm} / \mathrm{kg}$ change in knee adduction moment (KAM). 
Table 1. Mean values of coronal plane knee moments in stance phase $(\mathrm{N}=32)$

\begin{tabular}{|c|c|c|c|}
\hline & Shoe conditions & Knee sides & Mean \pm SD \\
\hline \multirow{5}{*}{$\begin{array}{l}\text { Knee adduction } \\
\text { moment } 1^{\text {st }} \text { peak } \\
0-25 \% \text { stance }(\mathrm{Nm} / \mathrm{kg})\end{array}$} & \multirow{3}{*}{ Flex-OA } & Right & $-0.413 \pm 0.143$ \\
\hline & & & \\
\hline & & Left & $-0.427 \pm 0.121$ \\
\hline & \multirow[b]{2}{*}{ Standardized } & Right & $-0.456 \pm 0.143$ \\
\hline & & Left & $-0.472 \pm 0.123$ \\
\hline \multirow{4}{*}{$\begin{array}{c}\text { Knee adduction } \\
\text { moment at mid stance } \\
25-75 \% \text { stance } \\
(\mathrm{Nm} / \mathrm{kg})\end{array}$} & \multirow[b]{2}{*}{ Flex-OA } & Right & $-0.136 \pm 0.082$ \\
\hline & & Left & $-0.199 \pm 0.101$ \\
\hline & \multirow{2}{*}{ Standardized } & Right & $-0.152 \pm 0.072$ \\
\hline & & Left & $-0.204 \pm 0.106$ \\
\hline \multirow{4}{*}{$\begin{array}{l}\text { Knee adduction } \\
\text { moment } 2^{\text {nd }} \text { peak } \\
75-100 \% \text { stance } \\
(\mathrm{Nm} / \mathrm{kg})\end{array}$} & \multirow[b]{2}{*}{ Flex-OA } & Right & $-0.323 \pm 0.117$ \\
\hline & & Left & $-0.371 \pm 0.118$ \\
\hline & \multirow[t]{2}{*}{ Standardized } & Right & $-0.319 \pm 0.108$ \\
\hline & & Left & $-0.379 \pm 0.116$ \\
\hline
\end{tabular}


Table 2. Repeated measure ANOVA comparing coronal plane knee moments under the shoe conditions and knee sides in stance phase during walking $(\mathrm{N}=32)$

\begin{tabular}{cccc}
\hline Moment values & Level & $\mathrm{F}$ & $\mathrm{p}$ \\
\hline $\begin{array}{c}\text { Knee adduction } \\
\text { moment } 1^{\text {st }} \text { peak } \\
0-25 \% \text { stance } \\
(\mathrm{Nm} / \mathrm{kg})\end{array}$ & Shoe conditions & 26.018 & 0.000 \\
Knee sides & 0.522 & 0.477 \\
$\begin{array}{c}\text { Knee adduction } \\
\text { moment at mid stance } \\
25-75 \% \text { stance } \\
(\mathrm{Nm} / \mathrm{kg})\end{array}$ & $\begin{array}{c}\text { Shoe conditions } \\
\text { Knee sides }\end{array}$ & 0.063 & 0.804 \\
Knee adduction & Conditions ${ }^{*}$ sides & 13.479 & 0.017 \\
moment $2^{\text {nd }}$ peak & Shoe conditions & 0.135 & 0.001 \\
$75-100 \%$ stance & Knee sides & 5.853 & 0.231 \\
$(\mathrm{Nm} / \mathrm{kg})$ & Conditions ${ }^{*}$ sides & 0.956 & 0.716 \\
\hline
\end{tabular}


Table 3. Mean values of clinical and biomechanical assessments and t-tests between responders and non-responders

\begin{tabular}{|c|c|c|c|}
\hline & $\begin{array}{l}\text { Responders } \\
\quad\left(\mathrm{n}_{1}=42\right)\end{array}$ & $\begin{array}{l}\text { Non-responders } \\
\qquad\left(\mathrm{n}_{2}=22\right)\end{array}$ & $\mathrm{P}$ \\
\hline Different KAM $(\mathrm{Nm} / \mathrm{Kg})$ & $0.08 \pm 0.06$ & $-0.03 \pm 0.05$ & $<0.001$ \\
\hline FPI (score) & $2.16 \pm 2.48$ & $2.89 \pm 3.26$ & 0.661 \\
\hline \multicolumn{4}{|l|}{ Hip rotation range } \\
\hline Internal rotation (degree) & $41.21 \pm 12.97$ & $43.72 \pm 14.54$ & 0.526 \\
\hline External rotation (degree) & $52.95 \pm 11.50$ & $41.16 \pm 13.46$ & 0.002 \\
\hline Ratio & $0.86 \pm 0.51$ & $1.21 \pm 0.70$ & 0.044 \\
\hline \multicolumn{4}{|l|}{ Hip rotators strength } \\
\hline Internal rotators (kgf) & $7.94 \pm 2.73$ & $8.95 \pm 2.55$ & 0.197 \\
\hline External rotators (kgf) & $10.05 \pm 3.55$ & $9.71 \pm 2.85$ & 0.731 \\
\hline Ratio & $0.81 \pm 0.19$ & $0.97 \pm 0.30$ & 0.028 \\
\hline \multicolumn{4}{|l|}{ AFMT rearfoot } \\
\hline Coronal motion (degree) & $29.05 \pm 7.63$ & $29.60 \pm 7.73$ & 0.804 \\
\hline Transverse motion (degree) & $22.84 \pm 7.14$ & $24.14 \pm 6.28$ & 0.514 \\
\hline Ratio & $1.43 \pm 0.81$ & $1.31 \pm 0.49$ & 0.581 \\
\hline \multicolumn{4}{|l|}{ AFMT midfoot } \\
\hline Coronal motion (degree) & $5.70 \pm 2.45$ & $6.11 \pm 2.46$ & 0.565 \\
\hline
\end{tabular}


Transverse motion (degree)

Ratio
$13.43 \pm 5.25$

$0.45 \pm 0.17$
0.584

0.963

KAM differential means different knee adduction moment value between OA-Flex and standardized shoe condition. $\mathrm{KAM}=$ Knee Adduction Moment, FPI = Foot Posture Index, IR = Internal Rotation, $\mathrm{ER}=$ External Rotation, AFMT $=$ Ankle Foot Motion Test 


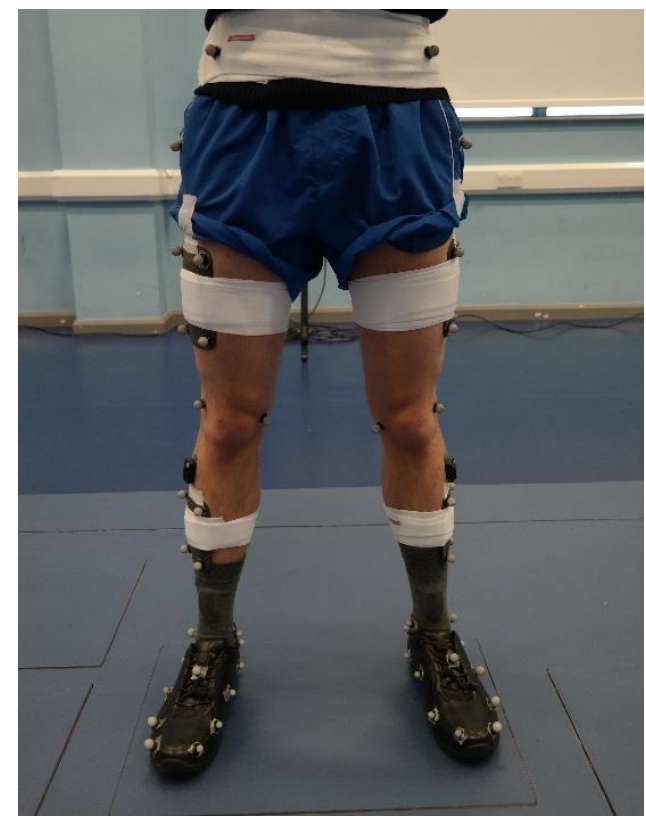

Figure 1. Marker positions on lower limbs and pelvic during static calibration and walking trials.

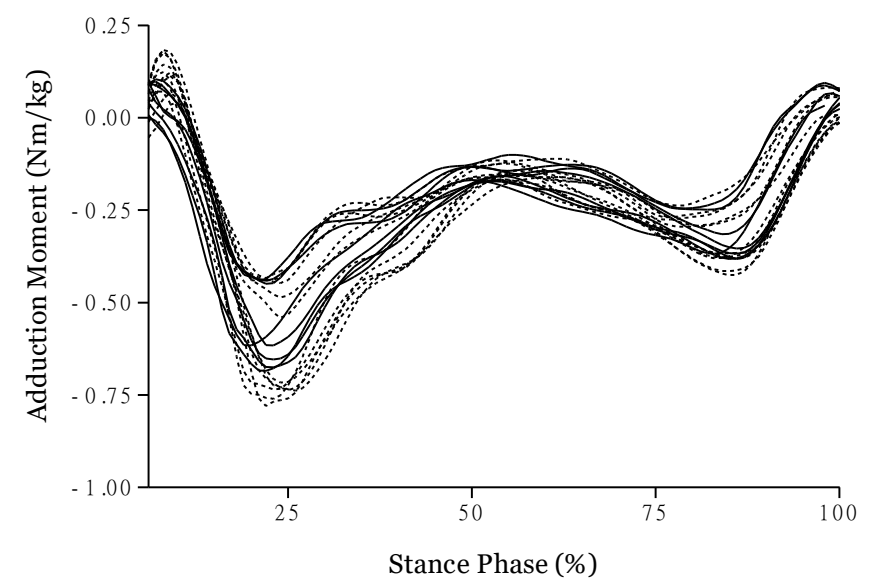

Figure 2. Intra-individual variability of knee adduction moment during stance phase. Flex-OA shoe moment (solid line) and standardized shoe moment (dot line) from 25 repetitive trials (thin line) and their average (thick lines). 


\section{Responders and Non-responders to the FlexOA Shoe}

0.3

0.25

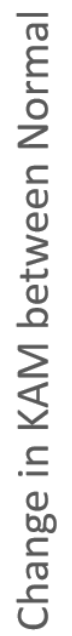

$$
0.2
$$

0.15

¿

$\sum_{4} \quad 0.1$

ฮำ

立

0

\|\|$\||| \mid$

$-0.05$

$-0.1$

$-0.15$

Participant/side number $n=64$

Figure 3. Biomechanical responders/non-responders to the Flex-OA shoe defined by a threshold of a

$0.02 \mathrm{Nm} / \mathrm{kg}$ change in knee adduction moment (KAM).

\section{REFERENCES}

1. Nam CW, Kim K, Lee HY. The influence of exercise on an unstable surface on

the physical function and muscle strength of patients with osteoarthritis of the knee. J Phys Ther Sci 2014; 26: 1609-1612 
2. Sharma L, Dunlop DD, Cahue S, Song J, Hayes KW. Quadriceps strength and osteoarthritis progression in malaligned and lax knees. Ann Intern Med 2003; 138: 613-619

3. Kaufman KR, Hughes C, Morrey BF, Morrey M, An KN. Gait characteristics of patients with knee osteoarthritis. J Biomech 2001; 34: 907-915

4. Baliunas AJ, Hurwitz DE, Ryals AB, Karrar A, Case JP, Block JA, Andriacchi TP. Increased knee joint loads during walking are present in subjects with knee osteoarthritis. Osteoarthritis Cartilage 2002; 10: 573-579

5. Thorp LE, Sumner DR, Block JA, Moisio KC, Shott S, Wimmer MA. Knee joint loading differs in individuals with mild compared with moderate medial knee osteoarthritis. Arthritis Rheum 2006; 54: $3842-3849$

6. Chiba T, Yamanaka M, Samukawa M, Saito H, Sabashi K, Tohyama H. The relationship between the load on the knee joint during walking and the biomechanical characteristics of single-leg standing. J Phys Ther Sci 2016; 8: 2199-2203

7. Sharma L, Hurwitz DE, Thonar EJ, Sum JA, Lenz ME, Dunlop DD, Schnitzer TJ, Kirwan-Mellis G, Andriacchi TP. Knee adduction moment, serum hyaluronan level, and disease severity in medial tibiofemoral osteoarthritis. Arthritis Rheum 1998; 41: 1233-1240 
8. Baker K, Goggins J, Xie H, Szumowski K, LaValley M, Hunter DJ, Felson DT. A randomized crossover trial of a wedged insole for treatment of knee osteoarthritis. Arthritis Rheum 2007; 56: $1198-1203$

9. Shelburne KB, Torry MR, Steadman JR, Pandy MG. Effects of foot orthoses and valgus bracing on the knee adduction moment and medial joint load during gait. Clin Biomech 2008; 23: 814-821

10. Kutzner I, Küther S, Heinlein B, Dymke J, Bender A, Halder AM, Bergmann G. The effect of valgus braces on medial compartment load of the knee joint - in vivo load measurements in three subjects. J Biomech 2011; 44: 1354-1360

11. Shakoor N, Lidtke RH, Sengupta M, Fogg LF, Block JA. Effects of specialized footwear on joint loads in osteoarthritis of the knee. Arthritis Rheum 2008; 59: 1214-1220

12. Radzimski AO, Mündermann A, Sole G. Effect of footwear on the external knee adduction moment - A systematic review. Knee 2012; 19: 163-175

13. Erhart-Hledik JC, Elspas B, Giori NJ, Andriacchi TP. Effect of variable-stiffness walking shoes on knee adduction moment, pain, and function in subjects with medial compartment knee osteoarthritis after 1 year. J Orthop Res 2012; 30: 514-521 
14. Shakoor N, Lidtke RH, Wimmer MA, Mikolaitis RA, Foucher KC, Thorp LE, Fogg LF, Block JA. Improvement in knee loading after use of specialized footwear for knee osteoarthritis: results of a sixmonth pilot investigation. Arthritis Rheum 2013; 65: 1282-1289

15. Collins TD, Ghoussayni SN, Ewins DJ, Kent JA. A six degrees-of-freedom marker set for gait analysis: repeatability and comparison with a modified Helen Hayes set. Gait Posture 2009; 30: 173180

16. Hatfield GL, Cochrane CK, Takacs J, Krowchuk NM, Chang R, Hinman RS, Hunt MA. Knee and ankle biomechanics with lateral wedges with and without a custom arch support in those with medial knee osteoarthritis and flat feet. Journal of Orthopaedic Research 2016; 34(9): 1597-1605

17. Long MJ, Papi E, Duffell LD, McGregor AH. Predicting knee osteoarthritis risk in injured populations. Clinical Biomechanics 2017; 47: 87-95

18. Chapman GJ, Parkes MJ, Forsythe L, et al. Ankle motion influences the external knee adduction moment and may predict who will respond to lateral wedge insoles?: an ancillary analysis from the SILK trial. Osteoarthritis Cartilage 2015; 23: 1316-22

19. Redmond AC, Crosbie J, Ouvrier RA. Development and validation of a novel rating system for scoring standing foot posture: the Foot Posture Index. Clin Biomech 2006; 21: 89-98

20. Cornwall MW, McPoil TG, Lebec M, Vicenzino B, Wilson J. Reliability of the modified Foot Posture Index. J Am Podiatr Med Assoc 2008; 98: 7-13. 
21. Cibulka MT, Strube MJ, Meier D, Selsor M, Wheatley C, Wilson NG, Irrgang JJ. Symmetrical and asymmetrical hip rotation and its relationship to hip rotator muscle strength. Clin Biomech 2010; 25: $56-62$

22. Kendall FP, McCreary EK, Provance PG, Rodgers MM, Romani WA. Muscle Testing and Function with Posture and Pain. Lippincott Williams and Wilkins; 2005.

23. Lafayette Instrument. Lafayette Manual Muscle Test System User. Instructions, Lafayette, Ind, USA, Lafayette Instrument; 2012.

24. Arazpour M, Hutchins SW, Bani MA, Curran S, Aksenov A. The influence of a bespoke unloader knee brace on gait in medial compartment osteoarthritis: A pilot study. Prosthetics and Orthotics International 2014; 38(5); 379-386

25. Jones RK, Nester CJ, Richards JD, Kim WY, Johnson DS, Jari S, Laxton P, Tyson SF. A comparison of the biomechanical effects of valgus knee braces and lateral wedged insoles in patients with knee osteoarthritis. Gait Posture 2013; 37(3):368-72.

26. Roos EM, Lohmander LS. The Knee injury and Osteoarthritis Outcome Score (KOOS): from joint injury to osteoarthritis. Health and Quality of Life Outcomes 2003; 1:64. 
27. Roaas A, Andersson GB. Normal range of motion of the hip, knee and ankle joints in male subjects, 30-40 years of age. Acta Orthop Scand 1982; 53: 205-208

28. Ellison JB, Rose SJ, Sahrmann SA, Patterns of hip rotation range of motion: a comparison between healthy subjects and patients with low back pain. Phys Ther 1990; 70: 537-741

29. Van Dillen LR, Bloom NJ, Gombatto SP, Susco TM. Hip rotation range of motion in people with and without low back pain who participate in rotation-related sports. Phys Ther Sport 2008; 9: 72-81.

30. Tönnis D, Heinecke A. Diminished femoral antetorsion syndrome: a cause of pain and osteoarthritis. J Pediatr Orthop 1991; 11: 419-431

31. Cibulka MT. Determination and significance of femoral neck anteversion. Phys Ther 2004; 84 : $550-558$

32. Stief F, Böhm H, Schwirtz A, Dussa CU, Döderlein L. Dynamic loading of the knee and hip joint and compensatory strategies in children and adolescents with varus malalignment. Gait Posture 2011; 33: 490-495.

33. Mirzaie G, Kajbafvala M, Rahimi A, Manshadi FD, Kalantari KK. Altered Hip Mechanics and Patellofemoral Pain: A Review of Literature. Ortop Traumatol Rehabil 2016; 18: 215-221 
34. Powers CM. The influence of altered lower-extremity kinematics on patellofemoral joint dysfunction: a theoretical perspective. J Orthop Sports Phys Ther 2003; 33: 639-646.

35. Hewett TE, Myer GD, Ford KR, Heidt RS Jr, Colosimo AJ, McLean SG, van den Bogert AJ, Paterno MV, Succop P. Biomechanical measures of neuromuscular control and valgus loading of the knee predict anterior cruciate ligament injury risk in female athletes: a prospective study. Am J Sports Med 2005; 33: 492-501

36. Sharma L, Song J, Dunlop D, Felson D, Lewis CE, Segal N, Torner J, Cooke TD, Hietpas J, Lynch J, Nevitt M. Varus and valgus alignment and incident and progressive knee osteoarthritis. Ann Rheum Dis 2010; 69: 1940-1945

37. Hurwitz DE, Ryals AB, Case JP, Block JA, Andriacchi TP. The knee adduction moment during gait in subjects with knee osteoarthritis is more closely correlated with static alignment than radiographic disease severity, toe out angle and pain. J Orthop Res 2002; 20: 101-107

38. Miyazaki T, Wada M, Kawahara H, Sato M, Baba H, Shimada S. Dynamic load at baseline can predict radiographic disease progression in medial compartment knee osteoarthritis. Ann Rheum Dis $2002 ; 61: 617-622$

39. Rokkedal-Lausch T, Lykke M, Hansen MS, Nielsen RO. Normative values for the foot posture index between right and left foot: a descriptive study. Gait Posture 2013; 38: 843-846 